\title{
LEYES DE DEFENSA DEL CONSUMIDOR Y DE SEGUROS. UNA TENSIÓN CONSTANTE EN EL DERECHO ARGENTINO
}

\author{
Federico M. Álvarez Larrondo*
}

Fecha de recibido: 23 de septiembre de 2013

Fecha de aprobado: 6 de diciembre de 2013

Artículo de reflexión

Forma de citación: Álvarez, F. M. (2013). Leyes de defensa del consumidor y de seguros. Una tensión constante en el derecho argentino. Revista Prolegómenos. Derechos y Valores, 16, 32, 135-158.

\section{Resumen}

El Derecho del Consumo (o del consumidor, según la postura que se adopte), a partir de la sanción de la Ley 24.240 en el año 1993, pero fundamentalmente, con la incorporación expresa en la Constitución Nacional reformada en el año 1994, del artículo 42 que consagra los derechos de consumidores y usuarios, ha trastocado un ordenamiento pétreo y anclado en las ideas propias de la Revolución Francesa (fuente de nuestro Código Civil vigente), dando paso a un sistema ajustado a la sociedad de consumo, masificada y predispuesta, que ha forzado a revisar posturas, análisis y hasta creencias. De allí entonces que este trabajo pretenda esbozar los cambios y debates generados en un campo puntual como lo es el ámbito de la actividad aseguradora, y los efectos del nuevo bloque constitucional-legal de consumo sobre la práctica asegurativa.

\section{Palabras Clave}

Constitución Argentina, Derecho del Consumo, Defensa del Consumidor, Contratos de Seguros

\section{CONSUMER DEFENSE AND INSURANCE LAWS. A CONSTANT TENSION IN ARGENTINEAN LAW}

\begin{abstract}
The Consumption Law (or Consumer Law, depending on the posture adopted), since the enactment of Law 24,240 in 1993, and more exactly, with the express incorporation of article 42 in the 1994 amended Constitution, which enshrines the rights of consumers and users, has overturned a system anchored in the ideas of the French Revolution (source of the current Argentinean Civil Code), giving way to a system adjusted to the consumer society, overcrowded and biased, that has forced the review of postures, analysis and even beliefs. From there, this work intends to outline the changes and debates generated in an exact field such as the
\end{abstract}

Universidad Nacional de Mar del Plata. Universidad FASTA (Santo Tomás de Aquino). Argentina. 
insurance business, and the effects of the new constitutional-legal block of consumption over the insurance practice.

\title{
Keywords
}

Constitution of Argentina, Consumer Law, Consumer Protection, Insurance Contracts

\section{DE DEFESA DO CONSUMIDOR E DE SEGUROS LEIS. A TENSÃO CONSTANTE NA LEI ARGENTINA}

\begin{abstract}
Resumo
A Lei de Consumo (ou Direito do Consumidor, dependendo da postura adotada), desde a promulgação da Lei 24.240, em 1993, e mais precisamente, com a incorporação expressa do artigo 42 em 1994 alterada Constituição, que consagra os direitos dos consumidores e usuários, anulou um sistema ancorado nas idéias da Revolução Francesa (fonte do atual Código Civil argentino), dando lugar a um sistema ajustado para a sociedade de consumo, superlotada e tendenciosa, que forçou a revisão de posturas, análise e até mesmo crenças. A partir daí, este trabalho pretende delinear as mudanças e os debates gerados em um campo exatamente como o negócio de seguros, bem como os efeitos do novo bloco constitucional-legal de consumo ao longo da prática de seguros.
\end{abstract}

\section{Palavras-chave}

Constituição da Argentina, Direito do Consumidor, Defesa do Consumidor, Contratos de Seguro.

\section{1.- INTROITO}

El Derecho argentino enfrenta, desde hace veinte años, una dura lucha entre dos posiciones claramente enfrentadas, respecto de la independencia o la interferencia en la ley de seguros, de la ley de defensa del consumidor. Esta discusión, de más está decirlo, está marcada por la natural puja entre los sectores enfrentados, donde las empresas aseguradoras reniegan y contraponen su ley a la de la defensa de los consumidores, y donde los usuarios, por el contrario, entronizan a la Ley 24.240 como centro del universo jurídico, y con ello, su primacía sobre el régimen asegurador.

Bien señala el destacado Fulvio Santarelli que

(...) el avance de las instituciones jurídicas suele generar fricciones interpretativas; la irrupción del derecho del consumidor, con su impronta transversal, no fue la excepción; máxime cuando la normativa consumerista va ganando en innovaciones que, cada vez más, reclaman una sincronización con el resto del ordenamiento. Esta realidad desordenada conlleva a disputas valorativas en el intérprete, quien construye su "pirámide" normativa a partir de una cierta escala de valores, dando como resultado lecturas de las más diversas, cuando no antagónicas. Este es el panorama que presenta en la doctrina nacional la relación entre el derecho de consumo y el régimen del contrato de seguro (Santarelli, 2010).

No obstante, entendemos que en esta materia de nada sirven los fundamentalismos, sino que es menester realizar un análisis integral que permita aplicar la ley de defensa del consumidor como «purificador legal» al decir del Ministro de la Corte Eugenio Raúl Zaffaroni, del muchas veces abusivo texto de la Ley 17.418 del 30 de agosto 
de 1967, dictada durante el Gobierno de facto de Onganía. Y bien decimos que la ley de seguros resulta favorable a dicho sector, valiéndonos para ello de las sabias palabras de una de las figuras insigne de nuestro Derecho nacional, como Rubén Stiglitz. El destacado profesor argentino, bien recordaba en tiempos recientes que resulta menester una reforma de la citada ley

(...) pues nació mal y no precisamente por alguna razón atribuible a su inspirador Isaac Halperín. La redacción final quedó en manos de una Subcomisión integrada por el Gerente Legal de la Superintendencia de Seguros, por el autor del anteproyecto, por un representante de la Asociación Argentina de Compañías de Seguros y por otro de la Asociación de Aseguradores Extranjeros en la Argentina.

Y aconteció lo previsible: prevaleció la opinión mayoritaria, la del sector asegurador y, con ello, el abandono de normas esenciales del "Anteproyecto Halperín".

Lo real (lo acontecido) consistió, al cabo, en la supresión de disposiciones contenidas en el "Anteproyecto Halperín", establecidas con un criterio independiente que tenía, inequívocamente, como propósito, la preservación del equilibrio contractual y de la vida del vínculo. Finalmente, esas normas fueron reemplazadas por disposiciones que, innecesaria e injustamente, favorecían la posición contractual del asegurador ya sea suprimiendo la vida del contrato o el derecho del asegurado (Stiglitz, Compiani \& Piedecasas, 2011).

Es claro que con esta matriz, que cuenta con más de cuarenta años, resultaba una tarea titánica enfrentar una norma que pretende, precisamente, modificar aquello que en la génesis fue instalado como principio rector del sistema, tal como lo detalla Rubén Stiglitz.

Fue así que la ardua tarea fue encabezada por distintos autores, en los que sobresale, por su clara postura reformadora, el Profesor Augusto
Sobrino (2009a; 2009b; 2010; 2011a; 2011b; 2011c; 2011d; 2012e) a quien se opone en la actualidad como punta de lanza, Domingo López Saavedra (2010a; 2010b; 2010c; 2011 y 2012), generando un rico debate que tiene, como es natural, a la Justicia como su autoridad dirimente.

Es que como bien sostiene Santarelli en el comentario antes citado,

(...) la riqueza de la cuestión no se agota en pronunciarse en uno $u$ otro sentido respecto de la aplicabilidad de un régimen u otro. En verdad la respuesta negativa, que se empeña en una autonomía a ultranza del derecho de seguro, corre la misma suerte de quien pretende tapar el sol con la manos, ello así desde que, como ya señalara Irti, los estatutos especiales emergentes tienen indudables influencias que cargan de nuevos contenidos axiológicos a la normativa clásica que implica una innegable transformación en su aplicación y funcionamiento. Por su parte la respuesta afirmativa, lejos de solucionar alguna cuestión concreta per se, es el pórtico a una serie de problemas a resolver de allí en adelante. Por ello, anticipar que ( ) a partir de la consagración de los derechos del consumidor en el art. 42 de la Constitución Nacional, no pueden soslayarse la aplicación de las directivas de la Ley 24.240 (Adla, LIII$\mathrm{D}, 4125)$ y sus modificatorias al régimen del contrato de seguros; no importa anticipar el final de la historia, sino su principio; desde que el desafío que queda es el análisis de esa integración normativa.

Ese proceso de integración que -claro estáno significa superposición ni derogación, sino una convivencia transformadora de las realidades interpretativas de ambos regímenes que se nutren mutuamente de sus principios informadores; debe evitar extremos totalitarios de imposición; pero es inevitable la elección por parte del intérprete de un principio preponderante que presida la mirada de la cuestión. 
Así entonces, con esta base, invitamos al lector a avanzar en pos de los argumentos que sustentan una y otra postura, y fundamentalmente, la respuesta que los tribunales argentinos han dado en estas últimas décadas.

\section{FUNDAMENTOS DE LA POSTURA CONTRARIA A LA APLICACIÓN DE LA LEY 24.240 DE DEFENSA DEL CONSU- MIDOR AL CONTRATO DE SEGUROS}

Para sintetizar los argumentos de esta postura, citaremos aquí la posición esbozada por el ya mencionado López Saavedra (2010). Así, sostiene:

a.- Que bajo el texto original de la Ley 24.240 no existía supuesto alcanzado por la ley dado que según su artículo $1^{1}$, esta se aplicaba a los supuestos de adquisición o locación de cosas muebles, la prestación de servicios y la adquisición de inmuebles nuevos destinados a vivienda, y en ninguno de ellos no cuadraba el seguro, dado que en el contrato de seguro no se asume el cumplimiento de una obligaciones de hacer, sino una obligación a cargo del asegurador de dar sumas de dinero, atento ser la finalidad la de indemnizar los daños sufridos por el asegurado como consecuencia de un siniestro. Así entonces, en su opinión, las disposiciones de la Ley de Defensa del Consumidor no eran aplicables al contrato de seguro.

b.- Ni la Ley de Seguros así como tampoco la Ley 20.091 -esta última que rige exclusivamente la actividad aseguradora y reaseguradora en nuestro país según lo prescribe su artículo 8-fueron expresamente derogadas ni modificadas por la Ley 24.240.

\footnotetext{
Texto original Ley 24.240 ARTICULO 1 - Objeto. La presente ley tiene por objeto la defensa de los consumidores o usuarios. Se consideran consumidores o usuarios, las personas físicas o jurídicas que contratan a título oneroso para su consumo final o beneficio propio o de su grupo familiar o social:

a) La adquisición o locación de cosas muebles;

b) La prestación de servicios;

c) La adquisición de inmuebles nuevos destinados a vivienda, incluso los lotes de terreno adquiridos con el mismo fin, cuando la oferta sea pública y dirigida a persona indeterminadas.
}

c.- La Ley de Seguros es una ley especial, por lo que la ley general posterior no deroga ni modifica, implícita o tácitamente, la ley especial anterior.

d.- La modificación operada por la Ley 26.361 al artículo 1 de la Ley $24.240^{2}$, ha extendido el ámbito de aplicación de la norma y, con ello, al abarcar a todas las operaciones de adquisición $\mathrm{o}$ uso de bienes o servicios en forma gratuita $\mathrm{u}$ onerosa como destinatario final, en beneficio propio o de su grupo familiar o social, ha permitido argumentar sobre su aplicación al contrato de seguro. Ello, atento que si estamos a lo que dispone el artículo 2312 del Código Civil, son bienes aquellos objetos inmateriales susceptibles de tener valor -incluyendo tal concepto también a las cosas-por lo que los derechos patrimoniales susceptibles de tener un valor serían bienes y, a partir de allí, se podría sostener que el derecho que tiene un asegurado a ser indemnizado por su asegurador por las consecuencias de un evento siniestral amparado por una póliza de seguros emitida por éste último constituye, para dicho asegurado, un derecho patrimonial, es decir, un bien y, en consecuencia y como ya algunos autores lo han sostenido, al contrato de seguro le sería aplicable la normativa prevista en la Ley de Defensa del Consumidor con las reformas que resultan de la Ley 26.361. Sin embargo, una vez más sostiene la improcedencia de dicha postura, fundado en los siguientes argumentos:

* Reitera que como en la anterior oportunidad, las leyes 24.240 y 26.361 son generales que, aunque posteriores a la Ley de Seguros y a la

\footnotetext{
Texto vigente luego de la modificación Artículo $1 .^{\circ}$ Objeto. Consumidor. Equiparación. La presente ley tiene por objeto la defensa del consumidor o usuario, entendiéndose por tal a toda persona física o jurídica que adquiere o utiliza bienes o servicios en forma gratuita $u$ onerosa como destinatario final, en beneficio propio o de su grupo familiar o social. Queda comprendida la adquisición de derechos en tiempos compartidos, clubes de campo, cementerios privados y figuras afines. Se considera asimismo consumidor o usuario a quien, sin ser parte de una relación de consumo, como consecuencia o en ocasión de ella adquiere o utiliza bienes o servicios como destinatario final, en beneficio propio o de su grupo familiar o social, y a quien de cualquier manera está expuesto a una relación de consumo
} 
20.091, no derogaron, ni expresa ni tácitamente estas dos últimas, las que tienen el indudable carácter de leyes especiales;

* Las normas de las leyes de Defensa del Consumidor nacen con la finalidad de actuar como correctores en los contratos de oferta masiva pero no constituyen normas de fondo, sino que resultan reglas protectivas y correctoras, siendo complementarias y no sustitutivas de la regulación general contenida en los códigos de fondo y la legislación vigente;

* La Ley de Defensa del Consumidor tiene por objeto actuar como efectivo control de cláusulas contractuales predispuestas en los contratos de adhesión, cuando el Estado Nacional no interviene mediante un control genérico en determinadas actividades, como ocurre con el transporte aerocomercial, con el contrato de seguro y con la actividad aseguradora que se hallan sujetos a autoridades de aplicación específicas y a cuerpos normativos especiales que incluyen convenciones internacionales ratificadas por nuestro país -por ejemplo, la Convención de Varsovia de 1929, el Protocolo de Montreal de 1999, la Convención de Bruselas de 1924 sobre unificación de ciertas reglas en materia de conocimientos de embarque, etc.-.

Con base en estas ideas centrales, esta corriente repudia la aplicación de la ley de defensa del consumidor a la actividad aseguradora.

\section{FUNDAMENTOS DE LA POSTURA FAVORABLE A LA APLICACIÓN DE LA LEY 24.240 DE DEFENSA DEL CONSUMIDOR AL CONTRATO DE SEGUROS}

Para sintetizar esta posición, recurriremos a la pluma de Waldo Sobrino (2011), quien argumenta:

1) A raíz del dictado del artículo 42 de la Constitución Nacional, la Ley de Defensa del Consumidor y la, importantísima, Ley 26.361, se produjo un giro copernicano en toda la normativa legal de nuestro país.
2) Como consecuencia de lo anterior, es que se debe realizar un «Test de Constitucionalidad» de absolutamente toda la normativa legal, para analizar si la legislación vigente se encuentra en consonancia y de acuerdo con el artículo 42 de la Carta Magna y la normativa consumerista.

3) El Código Civil ha sido modificado en varias de sus normas (v.gr. solidaridad, renuncia, daño, cadena de comercialización, cláusulas abusivas, contratos de adhesión, ampliación de la responsabilidad objetiva, responsabilidad por la actividad empresarial, legitimación pasiva, relación de consumo, interpretación de los contratos, efecto relativo de los contratos, prescripción, etc.).

4) Se creó un «Sistema Autónomo y Autorreferente» de Consumidores, donde se aplica, en escala jerárquica: (i) Elartículo 42 de la Constitución Nacional; (ii) Normativa Consumerista (Ley 24.240; Ley 24.999; Ley 26.361; etc.); y (iii) después -y siempre que no contradigan ni se opongan a las normas anteriores, que son jerárquicamente superiores-, se aplica: Código Civil, Código de Comercio, Ley de Seguros, etc.

5) La categoría legal de los «Consumidores de Seguros» se encuentra expresamente reconocida por la legislación vigente, $\mathrm{y}$, dentro de la misma, se encuentran las: (i) personas físicas; (ii) las empresas aseguradas, y (iii) las víctimas de siniestros.

6) La normativa consumerista no solo es aplicable a la legislación de seguros, sino que, además, modificó varias normas de la Ley de Seguros.

\section{EL ARGUMENTO DIRIMENTE: EL ARTÍCULO 42 DE LA CONSTITUCIÓN NACIONAL}

Creemos que la postura refractaria a la aplicación de la Ley 24.240 a los seguros omite siquiera tratar un argumento definitorio esbozado por el Profesor Sobrino, cual es la vigencia del artículo 42 de la Constitución Nacional, incorporado por la reforma operada en el año 1994. 
Dentro del capítulo de «Nuevos Derechos y Garantías», expresamente se consagran los derechos de los consumidores y usuarios, y en una redacción revolucionaria se establece:

Artículo 42.- Los consumidores y usuarios de bienes y servicios tienen derecho, en la relación de consumo, a la protección de su salud, seguridad e intereses económicos; a una información adecuada y veraz; a la libertad de elección, y a condiciones de trato equitativo y digno.

Las autoridades proveerán a la protección de esos derechos, a la educación para el consumo, a la defensa de la competencia contra toda forma de distorsión de los mercados, al control de los monopolios naturales y legales, al de la calidad y eficiencia de los servicios públicos, y a la constitución de asociaciones de consumidores y de usuarios.

La legislación establecerá procedimientos eficaces para la prevención y solución de conflictos, y los marcos regulatorios de los servicios públicos de competencia nacional, previendo la necesaria participación de las asociaciones de consumidores y usuarios y de las provincias interesadas, en los organismos de control.

Resulta menester entonces, previo a avanzar en nuestro análisis, establecer cuál ha sido a nuestro criterio el objetivo o finalidad fijada por el proceso constituyente del año 1994 al entronizar al consumidor como eje de una nueva sociedad, que había dejado de ser desde ya largo tiempo la sociedad del trabajo, de la producción, para convertirse en la sociedad de consumo.

El brillante sociólogo polaco Zygmunt Bauman, en una de sus tantas obras de lectura obligatoria para quienes quieran comprender la sociedad del siglo XXI en la que vivimos, explica que

(...) cuando decimos que la nuestra es una sociedad de consumo debemos considerar algo más que el hecho trivial, común y poco diferenciador de que todos consumimos. La nuestra es "una comunidad de consumidores" en el mismo sentido en que la sociedad de nuestros abuelos (la moderna sociedad que vio nacer la industria y que hemos descripto en el capítulo anterior) merecía el nombre de "sociedad de productores". Aunque la humanidad venga produciendo desde la lejana prehistoria y vaya a hacerlo siempre, la razón para llamar "comunidad de productores" a la primera forma de la sociedad moderna se basa en el hecho de que sus miembros se dedicaron principalmente a la producción; el modo como tal sociedad formaba a sus integrantes estaba determinado por la necesidad de desempeñar el papel de productores, y la norma impuesta a sus miembros era la de adquirir la capacidad y la voluntad de producir. En su etapa presente de modernidad tardía -esta segunda modernidad, o posmodernidad-, la sociedad humana impone a sus miembros (otra vez) principalmente la obligación de ser consumidores. La forma en que esta sociedad moldea a sus integrantes, está regida, ante todo y en primer lugar, por la necesidad de desempeñar ese papel; la norma que les impone, la de tener capacidad y voluntad de consumir. Pero el paso que va de una sociedad a otra no es tajante, no todos los integrantes de la comunidad tuvieron que abandonar un papel para asumir otro. Ninguna de las dos sociedades mencionadas pudo haberse sostenido sin que algunos de sus miembros, al menos, tuvieran a su cargo la producción de cosas para ser consumidas; todos ellos, por supuesto, también consumen. La diferencia reside en el énfasis que se ponga en cada sociedad; ese cambio de énfasis marca una enorme diferencia casi en todos los aspectos de esa sociedad, en su cultura y en el destino individual de cada uno de sus miembros. Las diferencias son tan profundas y universales, que justifican plenamente hablar de la sociedad actual como de una comunidad totalmente diferente de la anterior: una sociedad de consumo (Bauman, 2005, 44). 
En consecuencia, la aparición del artículo 42 de la Constitución Nacional no es un hecho fortuito, anecdótico o fruto de una postura "posmodernista», sino, muy por el contrario, un cambio de visión respecto del mundo y la confirmación, a partir de ese momento, de que nuestra Constitución reconocía en su texto el pasaje de aquella sociedad liberal productora de 1853 a esta sociedad social-consumista de finales del siglo XX. Este es el cambio más dramático del que se tenga memoria y que a la fecha no ha sido debidamente valorado.

Es que la citada norma constitucional ha optado, dentro de las corrientes propias del Derecho del Consumo, por la teoría maximalista en lugar de la restrictiva que enarbolaban los viejos artículos 1 y 2 de la Ley 24.240 (hoy modificados por la 26.361) y que, en verdad, ya habían quedado derogados por la manda constitucional. La nueva Ley 26.361 y los fundamentos expuestos en los debates parlamentarios confirman tal postura al afirmarse que, en verdad, la nueva ley viene a adecuar su texto al de la Carta Magna.

A partir de la reforma constitucional, entonces, el elemento activante del régimen tuitivo del consumidor dejó de ser el contrato de consumo, y pasó a ser una figura mucho más amplia, como lo es la relación de consumo.

Así, ya desde el año 1994, siempre que se estuviera ante una relación de consumo en cualquiera de sus etapas, se debía aplicar el sistema de protección del consumidor (Ver Lorenzetti, 2003), sin importar la existencia o no de vínculo contractual. Pero, a partir de la sanción de la Ley 26.361 , la protección va mucho más allá fijando como único recaudo el de revestir el carácter de destinatario final, aun fuera de una relación de consumo (Álvarez, 2008).

Con base en dichos antecedentes, sostenemos sin duda alguna que nuestra Carta Magna ha optado por adscribir dentro del Derecho del Consumo a la teoría maximalista que concibe al mismo como un ordenamiento superador de la idea de mero protector del consumidor final en su individualidad, erigiéndose, en cambio, en nodo central del orden económico, en marco legal regulador por excelencia del mercado del consumo íntegro superando la figura del individuo, es decir, objetivándose. Esto no es más que aggiornarse al marco social en el cual se inserta la actual Constitución: la sociedad de consumo.

(...) en Brasil los maximalistas ven en las normas del Código de Defensa del Consumidor $(\mathrm{CDC})$ una nueva regulación del mercado de consumo brasileño y no normas orientadas para proteger solamente al consumidor no profesional. El CDC sería un Código general sobre el consumo, un Código para la sociedad de consumo, el cual instituye normas y principios para todos los agentes del mercado, los cuales pueden asumir los papeles ya sea de fabricantes, ya sea de consumidores. La definición del artículo 2 debe ser interpretada lo más extensamente posible, según esta corriente, para que las normas del CDC puedan ser aplicadas a un número cada vez mayor de relaciones en el mercado" (Traducción personal) (Lima, 2000, 254).

Así entonces, lo expuesto cambia todo lo conocido en materia de «derecho económico», atento a que hasta la incorporación del artículo 42, las leyes de lealtad comercial y de defensa de la competencia eran las herramientas reguladoras del mercado. Y respecto de estas, sus comentaristas y la jurisprudencia surgida en torno a las mismas, explicaban con total claridad que su objetivo inmediato era el de proteger la libre y sana competencia en el mercado, preocupados por fijar reglas claras entre comerciantes con una idea propia del Medioevo. Al respecto, Carlos Vela afirma que

Resumiendo las diferentes posturas adoptadas por los tribunales, podría señalarse que el bien jurídico que se pretende proteger es la lealtad que debe reinar en las relaciones comerciales, lo cual deriva en la protección de los comerciantes competidores entre sí y los consumidores. Ahora 
bien, la conclusión a la que se arriba precedentemente deja muy poco margen para quienes sostienen que la ley de lealtad comercial protege un solo bien jurídico. En efecto, es claro que podría sostenerse que se pretende proteger la lealtad que debe haber en las relaciones comerciales entre los diferentes comerciantes y, por otro lado, se protege a los consumidores de las prácticas desleales que eventualmente quieran imponer los comerciantes. Por lo tanto, y es opinión del suscripto que la ley de lealtad comercial protege diversos bienes jurídicos (2004, p. 169).

De tal manera, con esa impronta idealizada de la mano invisible del mercado, se llegaba a la conclusión de que la pelea sincera y pura entre los empresarios terminaría de manera mediata protegiendo los intereses de los consumidores. Sin embargo, la realidad ha demostrado que no se ha logrado ni una cosa ni la otra. El consumidor en la realidad cotidiana (al menos en la Argentina) jamás recibió los beneficios «indirectos» proclamados por dichas normas. Por ello, el régimen legal argentino ha dado un vuelco radical en la materia, tomando conciencia de que el mercado solo puede fiscalizarse y regularse de manera efectiva invirtiendo los roles hasta ahora concebidos para los distintos agentes del campo negocial. Que la mano invisible del mercado no era más que una falacia de adoctrinamiento en pos de asegurar la mayor tasa de ganancia posible para quienes fueron empleadores del administrativo Adam Smith, y quienes resultan propietarios de las universidades que han difundido sus enseñanzas y acallado a quienes demostraron científicamente que tales elucubraciones no eran ciertas ${ }^{3}$.

En el ordenamiento construido a partir del artículo 42 de la Constitución Nacional, el consumidor ha dejado de ser el actor de reparto (beneficiario indirecto de las normas reguladoras del mercado)

3 Sobre el particular, resulta de sumo interés la lectura de la avezada y clarificadora obra de Walter Graziano, titulada con finalidad convulsionante "Hitler ganó la guerra", en particular el capítulo I "Nash: la punta del ovillo" (Graziano, 2007). y, muy por el contrario, es el ordenamiento legal originariamente surgido en razón de su persona el que persigue en la actualidad el albur del mercado justo declamado por los defensores del "libre comercio" (y lo hace de manera mucho más eficiente, vale decirlo). Y ello es lógico y plausible. Es que en la realidad cotidiana, salvo la actuación de oficio de la autoridad de contralor (lógicamente incapaz de alcanzar todos los sucesos violatorios de la diáfana competencia atento a contar con recursos finitos), es raro ver que un empresario inicie una acción judicial o administrativa contra otro par, fundado en que la publicidad de este es engañosa y que le quita mercado, puesto que, de seguro, él mismo tiene también sus prácticas que esconder. Solo lo hará cuando la contraria realice publicidad comparativa que afecte su imagen o marca (CNFed. Civ. y Com., Mayo 19 de 2005), pero no cuando la empresa competidora promocione falsas calidades de bienes o servicios, sin efectuar referencia alguna a los suyos. Por lo tanto, en Argentina ningún empresario denuncia a su par infractor, tal vez por el temor a las represalias o a ser él quien en el futuro se encuentre en el sillón de los acusados. Rige en verdad, como en la teoría de los juegos, el denominado «dilema del preso» ${ }^{4}$. Si ninguno «traiciona» al otro, no se podrá probar el delito, y así, la víctima (en este caso el consumidor supuestamente beneficiado por el sistema legal construido) se quedará sin Justicia.

$4 \quad$ El Dilema del Prisionero (Prisoner's dilemma) es un modelo de conflictos muy frecuente en la sociedad que ha sido profundamente estudiado por la Teoría de los Juegos. Dos delincuentes son detenidos y encerrados en celdas de aislamiento de forma que no pueden comunicarse entre ellos. El alguacil sospecha que han participado en el robo del banco, delito cuya pena es diez años de cárcel, pero no tiene pruebas. Sólo tiene pruebas y puede culparles de un delito menor, tenencia ilícita de armas, cuyo castigo es de dos años de cárcel. Promete a cada uno de ellos que reducirá su condena a la mitad si proporciona las pruebas para culpar al otro del robo del banco. Las alternativas para cada prisionero pueden representarse en forma de matriz de pagos. La estrategia "lealtad" consiste en permanecer en silencio y no proporcionar pruebas para acusar al compañero. Llamaremos "traición" a la estrategia alternativa. 
Estos recursos técnicos que representan las leyes mercantiles han quedado desactualizados, por cuanto fueron pensados para otros tiempos donde el mercado era reducido y el Estado poderoso. En ese proyecto de actuación estatal, el denominado «Estado Policía» asumía el rol de fiscalización y control de todo cuanto sucediera en el comercio, cargando sobre sus espaldas la persecución y el castigo de las violaciones. El Estado lo era todo y en él se descargaba todo. El punto es que esa «ideología» ya no resulta acorde con nuestra realidad actual. El mercado se ha fragmentado y complejizado de un modo hasta ahora nunca visto.

Las personas jurídicas se multiplican a diario al compás de la bonanza económica de algunos sectores; las operaciones comerciales adquieren tecnicismos indescifrables $y$, ante este escenario, el Estado otrora portentoso, hoy asiste a su propio desborde y crisis, lo que lo torna ineficiente para cumplir con la tarea antiguamente asignada. De allí entonces que el Constituyente del 94 haya optado por consagrar como pilar fundamental del sistema regulador del mercado al Derecho del Consumo, el cual ha venido a romper con todo lo conocido, ampliando el número de fiscales de la ley, descargando el control, ya no solo en el Estado y en los inactivos empresarios, sino fundamentalmente en los consumidores, las asociaciones de consumidores y los nuevos organismos públicos de control con competencia en la materia, a nivel nacional, provincial y municipal, incluyendo a partir de la reciente reforma de la Ley 26.361 al Defensor del Pueblo de la Nación.

De esta manera, son estos ahora los agentes activos que denuncian las prácticas violatorias de sus derechos para, de esa manera, expulsar del mercado a quienes no actúan de manera leal. Y para que este control resulte efectivo se debe incentivar su participación. Ahora bien, la única manera de hacerlo es dictando normas desde el Estado que aseguren la intervención, sin temores, de estos nuevos agentes fiscalizadores del mercado, y la única manera de incentivarlos a fiscalizar es asegurándoles el acceso gratuito tanto al sistema de conciliación administrativa como a la instancia judicial montados por la Ley 24.240.

En concordancia, vale citar el comentario de Carlos A. Molina Sandoval respecto de la Ley 25.954 conocida como «ley del redondeo», modificatoria de la 22.802, por la cual se intenta poner finiquito a una práctica habitual de los comercios que, debido a la escasez monetaria de monedas de un centavo, promocionan productos con la intención de comercializarlos a un precio mayor. Esta práctica realizada en forma cotidiana distorsiona, aunque sea levemente, el mercado, ya que dicha maniobra, traducida en incontables operaciones diarias, puede producir una ganancia sin causa de millones de centavos, que en ciertas empresas tiene significación patrimonial, y puede, incluso, llegar a incidir en un determinado esquema de flujo de fondos. Así, y en relación al aspecto que aquí tratamos, el autor citado afirma bajo el subtítulo «VI.1. Ley de lealtad comercial», que (...) la ley establece una consecuencia evidente (que la diferencia será siempre a favor del consumidor). Sin embargo, cabe señalar que en la práctica difícilmente el consumidor iniciará la acción civil correspondiente para obtener dicha diferencia (de cosas nimias no se ocupa el pretor). No obstante ello, dicha conducta (de difícil acreditación) podrá acarrear la denuncia de una asociación de protección del consumidor y, de manera individual, en la autoridad de aplicación y la aplicación de las sanciones correspondientes.

Y la ventaja de este nuevo régimen es que los consumidores no tienen razón para temer a las posibles o eventuales represalias, como sí los empresarios. Así, el Derecho del Consumo ha declarado la vetustez e insuficiencia del viejo régimen (sin perjuicio de pasar a ser dichas normas complementarias del régimen tuitivo del consumidor), y en consecuencia, ha dado carta de ciudadanía a un régimen que lo ha cambiado todo y que, por lo tanto, excede la humilde figura del consumidor desvalido, para pasar a ser eje central de un mercado de reglas claras y competitivo. Es que cuando un consumidor denuncia 
una publicidad falsa y obtiene el cese de su difusión, no solo está protegiendo sus derechos y los de los demás consumidores, sino también, ahora indirectamente, los del competidor de esa empresa denunciada que iba a ver reducidos sus ingresos por la canalización de muchos de sus clientes a manos de quien, en verdad, no iba a dar un servicio mejor ni de mayor calidad de aquel que él ofrecía. Es que no debe olvidarse que el consumidor que adquiere un bien de mediana envergadura, una vez que ha optado por celebrar el vínculo con el comerciante desleal, en primer lugar, le resulta muy difícil romper el acuerdo una vez constatado el engaño $y$, a su vez, por lo general carece de fondos como para intentar una segunda compra con el que no lo engañó. Por ello, una elección equivocada, inducida por el inescrupuloso, saca del mercado a los que caen presos del engaño y de allí que la competencia pierda irremediablemente ${ }^{5}$.

Por ello, reitero, el Derecho del Consumo regula precisamente las «relaciones de consumo», pero desde un lugar diametralmente opuesto a lo hasta aquí conocido. El mercado ya no es un campo propio de las empresas, sino que ahora es un espacio en el que juega, y cada vez con mayor protagonismo, su verdadera razón de ser: el consumidor. De allí que el legislador esté conminado por la norma Constitucional a otorgar herramientas efectivas para que el nuevo cambio de paradigma se torne real, tal como lo ha hecho, y así lo veremos, con el beneficio de justicia gratuita.

Insistimos: todo cambió con la llegada del reformado artículo 42, que nos ha introducido en un nuevo tiempo y lugar, y más aún se ha profundizado con la aparición de la Ley 26.361.

Estamos ante un Derecho regulador del mercado, de esto ya no hay duda alguna. Por ello es que

5 En este sentido, es fundamental la lectura de una de las obras de la profunda serie de trabajos sobre cuantificación económica elaborada por el maestro Carlos Ghersi (2005), titulada "Contratos de consumo", donde analiza los patrones a considerar para la mensura del daño al consumidor, dando pautas matemáticas objetivas aplicables al tema citado. el eje del sistema ya no sea el sujeto consumidor final, sino la «relación de consumo», que no es más que el revival del originario vínculo «cadena de producción-consumo».

En síntesis, a través de la manda del artículo 42 de la Constitución Nacional que establece la teoría maximalista de regulación del mercado, es el consumidor el que puede ahora denunciar y requerir, tanto a la Justicia como a las autoridades administrativas, el cese de toda práctica distorsiva de la libre competencia y la lealtad comercial y, de allí, que el Derecho del Consumo no sea un "derecho menor», sino la rama más destacada del escenario actual. Y para ello, la gratuidad en el acceso a la Justicia es condición sine qua non para el efectivo funcionamiento del engranaje diseñado por el Constituyente.

Es con esta inteligencia, con esta línea rectora básica con la que debe analizarse el debate que motiva el presente estudio. Es imposible entender la temática a analizar, si antes no entendemos que el mundo de las ideas jurídicas ha cambiado; si no se comprende que tenemos ante nuestros ojos un nuevo paradigma instaurado por el Derecho del Consumo. En tal sentido, es preclaro el siguiente pasaje del por demás recomendable trabajo de Junyent Bas y Del Cerro, cuando afirman

En esta línea, cabe recordar que el término "paradigma" fue utilizado por primera vez por Thomas Kuhn e implica un cambio de "modelo" en los esquemas científicos, en este caso del ordenamiento jurídico. De tal modo, cuando se habla de un cambio de "paradigma", no pretende señalarse que se han modificado solamente determinados principios generales, sino que, por el contrario, la reformulación es de tal profundidad que estructura nuevamente el sistema epistemológico y, consecuentemente, la articulación del ordenamiento jurídico se realiza sobre nuevas bases. En el ámbito del derecho, predicar la existencia de un nuevo paradigma implica entonces señalar que ha surgido un nuevo modelo jurídico que requiere de la reestructuración de sus princi- 
pios fundantes y de los criterios de interpretación. De tal modo, el paradigma es "una matriz disciplinar", una "cosmovisión" que permite abordar la comprensión del ordenamiento jurídico a partir de determinadas premisas, en este caso, el consumidor como protagonista del funcionamiento de un mercado concurrencial en donde convergen las etapas de producción, comercialización y consumo. (...) Desde esta perspectiva, la tutela del consumidor o usuario se alza como una directriz central de todo el ordenamiento jurídico reconociendo no solamente su especial protección, sino también exigiendo que los procedimientos la efectivicen, de manera tal que la reforma impacta en los códigos de fondo y en el ámbito procesal. (...) En consecuencia, en una interpretación legal, si hubiera colisión entre una norma de derecho común y otra que protege a los consumidores, primará esta última. Por lo tanto, el régimen de derecho que surge de la LDC importa no sólo complementar sino también modificar o derogar, siquiera parcialmente, las normas de otras ramas jurídicas que se apliquen a la relación de consumo que concretamente se considere (Junyent \& Del Cerro, 2010).

Es por ello que solo una vez internalizado el cambio se podrá avanzar en un análisis ajustado a derecho del impacto de la ley de defensa del consumidor sobre el contrato de seguro.

\section{LOS PRINCIPALES ÁMBITOS EN LOS QUE EL DERECHO DEL CONSUMO HA MODIFICADO LA PRÁCTICA ASEGURATIVA}

Atento que el debate está echado, y los argumentos vertidos, entendemos fundamental destacar los ámbitos en los cuales la Justicia ha resuelto la aplicación de la Ley 24.240 en materia de seguros, citando tan solo los temas que consideramos de mayor impacto. A continuación, entonces, iremos desgranando una serie de interrogantes fundamentales.

\subsection{Primer interrogante: ¿es la empre- sa aseguradora un proveedor en los términos de la Ley 24.240?}

Sobre el particular los tribunales argentinos han dicho que

Ingresando al análisis de la cuestión debatida, se advierte que la misma se refiere a la interpretación de la pericia realizada por el A quo y a la aplicación del estatuto del consumidor, principalmente el principio "in dubio pro consumidor" esgrimido por el Sentenciante para resolver que la incapacidad padecida por el actor se inició durante la vigencia del contrato de seguros.

Coincido con el Sr. Fiscal de Cámaras en el sentido de que el régimen consumeril es aplicable a la presente causa por cuanto se trata de una relación de consumo en los términos de la Ley 24.240.

La demandada es una compañía de seguros que se dedica a la oferta de seguros en los términos de la ley que regula la actividad -Ley 17.418-, y como la normativa de defensa del consumidor no limita ni distingue la naturaleza del servicio, el caso de marras queda alcanzado por las previsiones de la Ley 24.240. La relación encuadra en la descripción del art. 1 de la mentada ley.

No cabe duda que la demandada es una -proveedora- de un servicio: el seguro. Su actividad encuadra en las previsiones del art. 2 del régimen consumerista, pues participa en la oferta de bienes y servicios en el mercado y al público indeterminado. La actividad aseguradora se encuentra alcanzada por las premisas del artículo mencionado.

Por otra parte, no están expresamente excluidas en el segundo párrafo (Cámara 6a de Apelaciones en lo Civil y Comercial de Córdoba, Octubre 8 de 2009). 


\subsection{Segunda cuestión: ¿el asegurado es consumidor?}

En el mismo precedente antes citado, el Tribunal sostuvo que

Aquí se trata de la prestación de un servicio, más concretamente, de la provisión de un seguro colectivo de vida por parte de la demandada a la actora. En efecto, la presente causa versa concretamente sobre el otorgamiento de un seguro de vida a la actora por parte de Seguros Bernardino Rivadavia Cooperativa Limitada, respecto del cual se discute la validez de la cláusula quinta de dicho instrumento (fs. 29 vta.), que establece que la invalidez total y permanente es un riesgo cubierto por el contrato, siempre que tal estado se hubiera iniciado durante la vigencia de su seguro.

Tampoco hay duda que el asegurado es un usuario o consumidor, por ello goza de una mayor protección como consecuencia de ser parte de una relación de consumo en virtud del régimen tuitivo aplicable.

Es desacertada cualquier interpretación que condicione o supedite la aplicación de la Ley 24.240 al hecho de que una ley especial como la Ley de Seguros- prevea mecanismos de protección para el consumidor.

Recordemos que la Ley 24.240 desde el enfoque imperativo de un plexo de orden público, se articula como bisagra en las relaciones de consumo, avanzando sobre el Derecho Público, en cuanto no parte de la igualdad y libertad de las personas involucradas, sino que trata de lograr esa igualdad o posibilitar una mayor libertad

Conforme surge del art. 42 de nuestra Carta Magna, el consumidor y/o usuario es protegido en sus derechos patrimoniales y la Ley 24.240 asume este enfoque y le reconoce una serie de acciones que aquél puede ejercitar a fin de mantener incólumes sus derechos frente al proveedor.
La normativa consumeril contiene un esquema de responsabilidad civil propio que prevalece sobre el previsto en el derecho común, aunque no excluye su aplicación y en diversos aspectos se complementa con él.

En la presente causa se encuentra discutida la aplicación del art. 37, el que junto con los arts. 38 y 39 constituyen una, al referirse a las cláusulas abusivas en los contratos de consumo, pieza fundamental del régimen de defensa del consumidor.

La primera de las normas mencionadas contiene una regla por la cual se regula la interpretación del contrato, estableciendo que "Sin perjuicio de la validez del contrato, se tendrán por no convenidas..." enunciando luego tres alternativas de cláusulas que la doctrina ha dado en llamar abusivas. Empero, esta enumeración, que es de carácter ejemplificativo y no taxativo, puede ser ampliado, siempre que del carácter de la cláusula, surja la lesión a los derechos del consumidor y pueda incluirse entre alguna de las tres alternativas legales.

Por su parte, es claro que la póliza base de la relación contractual entre actora y demandado, cae dentro de los rasgos que definen a un contrato tipo, de adhesión, con cláusulas predispuestas, que, cualquiera sea la denominación utilizada, autorizan su revisión judicial, por encontrarse expresamente previsto en el art. 38 de la Ley 24.240.

En tanto, la Cámara Civil y Comercial de Lomas de Zamora, Provincia de Buenos Aires, con invocación de la vieja redacción del artículo 1 de la Ley 24.240 sostuvo que

Al respecto cabe destacar que el art.1 del plexo en examen define qué se entiende por consumidor, a la vez que extiende dicho concepto a los usuarios, remarcando que se trata de personas físicas o jurídicas que contratan a título oneroso para consumo final o beneficio propio o de su grupo 
familiar o social: a) la adquisición o locación de cosas muebles; b) la prestación de servicios; c) la adquisición de inmuebles nuevos destinados a vivienda, incluso los lotes de terreno adquiridos con el mismo fin, cuando la oferta sea pública y dirigida a personas indeterminadas.

La demandada es una compañía de seguros que se dedica a la oferta de seguros en los términos de la ley que regula la actividad -Ley 17.418-, y como la normativa de defensa del consumidor no limita ni distingue la naturaleza del servicio, el caso de marras queda alcanzado por las previsiones de la Ley 24.240. La relación encuadra en la descripción del art. 1 de la mentada ley (Cámara de Apelaciones en lo Civil y Comercial de Lomas de Zamora, sala I, Mayo 22 de 2012).

\subsection{Tercer interrogante: ¿el contrato de seguro es un contrato de consumo?}

En tal sentido, se sostuvo que

Una primera pregunta, indefectible, es la siguiente: el contrato de seguro de vida y capitalización-que ya hemos admitido que es comercial porque así lo califica el paradigmático artículo 8. del Código de la materia-, ¿es un contrato de derecho del consumo?

Tampoco aquí tengo dudas en orden a que la respuesta es positiva, toda vez que la relación contractual comprometida claramente encuadra en el amplio concepto consumerista del artículo $1^{\circ}$ de la Ley 24240 (en tanto es un contrato celebrado entre un proveedor de servicios profesional y un adquirente a título oneroso que contrata para destinarlos a su consumo final o el de su grupo familiar), como sucede con los contratos de seguro en general (Farina, 2000, p. 72; Wajntraub, 2004, p. 27; Cámara de Apelaciones en lo Civil y Comercial de Santa Fe, sala I, Octubre 4 de 2006).

\subsection{Consecuencias de enmarcar al contrato de seguro como contrato de consumo}

\section{a) Aplicación del in dubio pro consumidor}

El artículo 3 reformado por la Ley 26.361 establece

Artículo $3 .^{\circ}$ - Relación de consumo. Integración normativa. Preeminencia. Relación de consumo es el vínculo jurídico entre el proveedor y el consumidor o usuario.

Las disposiciones de esta ley se integran con las normas generales y especiales aplicables a las relaciones de consumo, en particular la Ley $N^{\circ} 25.156$ de Defensa de la Competencia y la Ley $N^{\circ} 22.802$ de Lealtad Comercial o las que en el futuro las reemplacen. En caso de duda sobre la interpretación de los principios que establece esta ley prevalecerá la más favorable al consumidor.

Las relaciones de consumo se rigen por el régimen establecido en esta ley y sus reglamentaciones sin perjuicio de que el proveedor, por la actividad que desarrolle, esté alcanzado asimismo por otra normativa específica.

En sentido concordante con tal principio, los tribunales argentinos han dicho que

Por último, y como también lo destaca acertadamente el decidente, la interpretación que se realiza, no sólo encuentra apoyatura en aquellos principios que hemos enunciado -buena fe- sino que la propia Ley de Defensa del Consumidor -Ley 24240- obliga a adoptar la interpretación que favorezca los intereses del consumidor, pudiéndose subsumir en dicha categoría al tomador del seguro (Cámara de Apelaciones en lo Civil, Comercial y de Minería de Bariloche, Abril 4 de 2011). 
La Cámara Civil y Comercial de Pergamino, Provincia de Buenos Aires, sostuvo que

Ya nadie puede discutir que el contrato de seguro es un contrato de consumo regulado. (...) De lo que se sigue que resultan operativas normas tales como el principio de protección al más débil y que al decir de Lorenzetti "ya no se trata de un favor debitoris, sino de un favor debilis, ajustando el principio a las nuevas demandas que presenta la sociedad", el principio in dubio pro consumidor, la garantía de información veraz, suficiente, la garantía de indemnidad, la regulación de la publicidad, la fuerza vinculante de las precisiones publicitaris, la nulidad de cláusulas abusivas, todo ello expresamente previsto en los art. 2, 3, 4, 5,8 y 37 de la mentada ley (Cámara de Apelaciones en lo Civil y Comercial de Pergamino, Febrero 28 de 2012).

\section{b) El deber de información}

Entendemos que este es un tema central y dirimente del grueso de los conflictos judiciales. Vale recordar que la Ley 24.240, reforzando la obligación impuesta por el artículo 42 de la Constitución Nacional, en su artículo 4 dispone que

Información. El proveedor está obligado a suministrar al consumidor en forma cierta, clara y detallada todo lo relacionado con las características esenciales de los bienes y servicios que provee, y las condiciones de su comercialización.

La información debe ser siempre gratuita para el consumidor y proporcionada con claridad necesaria que permita su comprensión.

Pues bien, con base en esta norma se ha dicho que

(...) la obligación de la aseguradora en cuanto a su deber de informar resulta determinante, en aras de resolver la cuestión recurrida. Así se ha sostenido: "En este tipo de contrato -seguro de vida colectivo- el asegurado resulta ser "un consumidor", por lo que constituye un deber de la parte profesional el informar a la parte débil en forma cierta y eficaz. (Ccpa 02 Paraná, 202 52181 S Solaro Ruben P. C/ Sudamérica Seguros S/ Sumario, LDT Textos).

Por ello, a partir de la previsión del art. 4 de la Ley 24240, que establece que el deber de información, debe ser cierta y objetiva, información veraz, detallada y eficaz, de lo que se concluye que la simple notificación efectuada por la Asociación Mutual, mediante transparente en la sede, resulta insuficiente para sostener la inoponiblidad de la designación de beneficiario obrante a fs. 06 de auto.

Bajo tales condiciones de hecho y de derecho apuntadas, sólo cabe interpretar que la designación como beneficiario del seguro de vida colectivo del señor Francisco Vergara al señor Felipe Neri Vergara se encuentra plenamente vigente, debiendo en consecuencia confirmar la resolución apelada (Cámara de Apelaciones Civil y Comercial de Formosa, Marzo 3 de 2011).

En tanto, la Cámara en lo Civil y Comercial de Córdoba, en un caso en el cual debía resolver sobre una demanda de cobro de pesos intentada contra una aseguradora en virtud del seguro de vida colectivo contratado por el empleador del cónyuge del accionante, el Tribunal sostuvo que

La modificación unilateral de una cláusula efectuada por la aseguradora disminuyendo el riesgo cubierto del seguro de vida colectivo facultativo contratado, no le es oponible al asegurado, pues, aquella no cumplió con el deber de información que le impone la Ley de Defensa del Consumidor y el hecho de que la contratación hubiera sido facultativa no significa que el asegurado haya tenido oportunidad de conocer el contenido de la póliza, máxime cuando el asegurado no acreditó haber realizado aquellos actos tenientes a anoticiar a los consumidores adherentes de aquellas mo- 
dificaciones (Cámara 6a de Apelaciones en lo Civil y Comercial de Córdoba, Noviembre 9 de 2011).

Por su parte, la Cámara Nacional Civil resolvió que

Resulta abusiva la cláusula contenida en un contrato de seguro de responsabilidad civil en cuanto limita la cobertura a los daños ocasionados a terceros no transportados, excluyendo los causados a los transportados, pues la diferencia entre el contenido de dicha cláusula y lo declarado por el productor de seguros en relación al riesgo cubierto revela que en el caso no se cumplió satisfactoriamente con el deber impuesto al proveedor, por el art. 4 de la Ley 24.240, de informar con exactitud las características del seguro contratado (CNCiv., sala L, Abril 28 de 2009).

\section{c) Cláusulas abusivas}

Previo a adentrarnos una vez más en la temática que nos convoca, nos parece interesante traer a colación las enseñanzas que ya en la década pasada brindara el por entonces promotor de Justicia de Río do Sul, Brasil, Adalberto Pasqualotto(1993) respecto de la situación en el derecho comparado de la materia bajo estudio. El autor citado bien explicaba que las condiciones negociales generales han sido tema de preocupación en Europa desde mediados de la década del 70.

El Consejo de Europa tiene hechas recomendaciones respecto del control de las cláusulas abusivas, sugiriendo la creación de agencias administrativas para la realización de una actividad preventiva en la negociación directa de las cláusulas, o represiva, con legitimación para actuar en juicio. Recomienda también la creación de organismos parajudiciales (formados por representantes de los consumidores y de las empresas) competentes para decidir sobre las transgresiones a las directivas administrativas sobre las cláusulas.

Algunos países crearon leyes especiales como la de Alemania de 1976, la de Francia de 1978 y la de Portugal de 1985. Otras, como la de Italia, incorporaron la reglamentación de esta materia en su Código Civil.

Así, encontramos como una suerte de conclusión que en el mundo se han corporizado dos tipos de control: uno previo, realizado por órganos administrativos y otro posterior, realizado por órganos judiciales o parajudiciales. A continuación, nos adentramos en el análisis de cada uno de ellos.

\section{- El control preventivo}

El control previo puede ser ejercido por órganos públicos o por comisiones mixtas integradas por miembros del gobierno, empresarios y representantes de asociaciones de defensa del consumidor. Tienen carácter administrativo.

Uno de los sistemas es el que reserva esta facultad exclusivamente en manos del Estado. Otro, es el que se basa en la formación de comisiones mixtas conformadas por miembros del gobierno y por representantes de las clases empresariales y de las asociaciones de defensa del consumidor, a quienes se les encarga el control del cumplimiento de las condiciones negociables. Así, algunas comisiones dictan cláusulas que se consideran permitidas y cláusulas que se consideran prohibidas; otras, por su parte, apenas fiscalizan el mercado por medios que pueden incluir el registro previo obligatorio de las cláusulas y la suspensión de aquellas consideradas vejatorias.

La ley alemana exige que las cláusulas sean fijadas en letreros visibles al público en los locales y demás establecimientos que las utilizan, y consideran ineficaz cualquier cláusula sorpresa. La ley también establece dos catálogos: uno, con cláusulas relativamente prohibidas (que admiten apreciación judicial) y otro, que contiene cláusulas absolutamente prohibidas, nulas de pleno derecho. La misma técnica utiliza Portugal. En Finlandia, la ley de protección al consumidor de 1978 incluye una disposición general, que prohíbe las cláusulas abusivas en detrimento del consumidor, dejando a la jurisprudencia la casuística. 


\section{- El control represivo}

En este segundo gran capítulo en la materia, el control de las condiciones generales de los contratos es hecho, principalmente, por el Poder Judicial. Se le atribuye al juez un papel fundamental en la interpretación de las cláusulas, fundándose en valores éticos y morales, como la buena fe y las buenas costumbres o en figuras técnicas, como el abuso del derecho y el enriquecimiento sin causa. Pero el problema principal que enfrenta este tipo de control está dado por el acceso a la justicia, que se ve dificultado por el alto costo y por la demora en la solución de los litigios ante reclamaciones que, por lo general, están constituidas por valores monetariamente modestos.

Por su parte, otra corriente es partidaria de lograr el control de las cláusulas a través de negociaciones entre las asociaciones de consumidores y las entidades representativas de las clases empresariales a la manera de los convenios colectivos de trabajo. Por este tema venimos abogando desde largo tiempo y, a su vez, trabajando en un próximo proyecto de ley.

\subsection{El control de las cláusulas abusivas en la Ley 24.240}

Nuestra ley recepta el control de las cláusulas abusivas en sus dos fases, tanto la preventiva como la represiva. La primera la encontramos consagrada por los artículos 38 y 39, en tanto que a la segunda la hallamos en el artículo 37.

\section{a) Control preventivo}

El artículo 38 establece que la Autoridad de Aplicación ejercerá su facultad de vigilancia sobre los contratos de adhesión o similares a los fines de que los mismos no contengan cláusulas de las previstas en el artículo anterior, ejerciendo la misma atribución respecto de las cláusulas uniformes, generales o estandarizadas de los contratos hechos en formularios, reproducidos en serie y, en general, cuando dichas cláusulas hayan sido redactadas unilateralmente por el proveedor de la cosa o servicio, sin que la contraparte tuviere posibilidades de discutir su contenido.

De lo expuesto, surge que nuestra legislación ha consagrado un control previo netamente administrativista.

Por su parte, el artículo 39 establece que cuando los contratos a que se refiere el artículo anterior requieran la aprobación de otra autoridad nacional o provincial, esta tomará las medidas necesarias para la modificación del contrato tipo a pedido de la Autoridad de Aplicación.

\section{b) Control represivo}

El mismo se halla consagrado por el artículo 37, que establece: sin perjuicio de la validez del contrato, se tendrán por no convenidas:

- las cláusulas que desnaturalicen las obligaciones o limiten la responsabilidad por daños;

- las cláusulas que importen renuncia o restricción de los derechos del consumidor o amplíen los derechos de la otra parte;

- las cláusulas que contengan cualquier precepto que imponga la inversión de la carga de la prueba en perjuicio del consumidor.

El citado artículo enuncia que

La interpretación del contrato se hará en el sentido más favorable para el consumidor. Cuando existan dudas sobre los alcances de su obligación, se estará a la que sea menos gravosa.

En caso en que el oferente viole el deber de buena fe en la etapa previa a la conclusión del contrato o en su celebración o transgreda el deber de información, o la legislación de defensa de la competencia o de lealtad comercial, el consumidor tendrá derecho a demandar la nulidad del contrato o de una o más cláusulas. Cuando el juez declare la nulidad parcial, simultáneamente integrará el contrato, si ello fuera necesario. 
Pues bien, como puede observarse en la primera parte del artículo, el mismo lleva ínsito un doble criterio de calificación, dado que establece una serie de cláusulas «cerradas», precisas (v. gr. cláusulas que limiten la responsabilidad por daños), junto a las denominadas «abiertas» que dejan margen para que sea la Autoridad administrativa o el Juez según corresponda, el que en definitiva la interprete y genere la correspondiente casuística (v. gr. las cláusulas que importen renuncia o restricción de los derechos del consumidor o amplíen los derechos de la otra parte $)^{6}$.

Estas son las que calificamos como cláusulas abusivas de carácter objetivo, es decir, aquellas cuya inexistencia (no nulidad, de allí que no requieran declaración judicial que determine el vicio por cuanto directamente no forman parte del contrato) surge del solo confronte de su texto con la ley, y que se diferencian claramente de las que definimos como cláusulas abusivas de carácter subjetivo, las cuales sí deben ser declaradas nulas, pero a cuyo fin debe acreditarse un acompañamiento por acción u omisión por parte del co-contratante que hace que una cláusula que a primera vista resultaría válida, como producto de la violación del deber de buena fe, o de la falta de información, o de la violación de la ley de defensa de la competencia, o de lealtad comercial, se torne nula de nulidad absoluta.

Reiteramos, las primeras solo requieren un estudio técnico, mientras que las segundas exigen, además, la demostración de la actuación reñida con la buena fe, el deber de información, etc.

Ahora bien, en la parte final de este artículo se patentiza el control judiciario posterior, que se da cuando ha fallado el control administrativo previo o cuando el mismo no ha existido por no

6 Ver por ejemplo lo resuelto por el Juzgado Nacional de 1a Instancia en lo Civil núm. 110 (2008), donde se dijo que "resulta abusiva la cláusula inserta en un contrato de compraventa de automotor importado según la cual cualquier variación en el precio es a cargo del comprador, ya que, a efectos de mantener la igualdad de las partes ante las reglas del mercado, el contrato que establece un precio variable no puede prever sólo una variación para el caso de aumentos". ser un contrato que requiera aprobación previa $y$ no ha mediado denuncia de consumidor interesado o asociación de consumidores que hubiera tomado conocimiento.

No obstante, el hecho de que haya mediado aprobación por parte de un órgano administrativo no es óbice para la declaración posterior y judicial de la abusividad de una cláusula.

Hecho entonces este racconto, analizamos lo resuelto en la materia por nuestra Justicia argentina.

La Cámara Civil y Comercial de Dolores, Provincia de Buenos Aires, bien ha dicho que

La cláusula del contrato de seguro que para el supuesto de pérdida total del vehículo por daño o robo o hurto, condiciona el pago de la prima a la entrega por el asegurado de documentación complementaria que no es posible recabar por un hombre medio y requiere la contratación de un gestor, carece de valor Dart. 37, Ley 24.240de conformidad con el principio de razonabilidad, pues no se advierte la necesidad de entregar la totalidad de los documentos solicitados antes de que se haya fijado la fecha de pago.

Para así decidir tengo presente no sólo el contenido sino las posibilidades de cumplimiento del instructivo, teniendo en cuenta que la actividad de la aseguradora por la función social que cumple, requiere la máxima buena fe en su proceder con el asegurado, por el carácter profesional que reviste y por la distinta fuerza económica que existe entre ella y el asegurado. Por ello, la conducta de la aseguradora que califico de indiferente y tendiente a dejar transcurrir el tiempo para aprovecharlo en su favor, puesto que recién formuló a Cancio alguna manifestación por medio fehaciente en el momento de haberse conocido el hallazgo del automotor (fs. 399/400), hecho ocurrido a más de dos meses de producido el siniestro; merece una sanción que no es 
otra que el cumplimiento del contrato de seguro.

Por otra parte y aún de Perogrullo si la policía pudo informar a Mapfre que el vehículo estaba en su poder fue porque tenía conocimiento de que a ella debía hacerlo saber y no a Cancio, era aquella quien debía realizar las gestiones para el recupero atento la suficiente y oportuna denuncia de robo que realizara Cancio; de estos extremos me convencen el contenido de la carta documento de fs. 399 y el informe de fs. 366 (Cámara de Apelaciones en lo Civil y Comercial de Dolores, Octubre 25 de 2011).

En tanto en un precedente de comienzos de siglo, se ha dicho que resulta nula la cláusula que exige la identificación del otro rodado implicado en un siniestro para tornar operativa la cobertura del seguro. Así se sostuvo que

La cláusula que exige como condición para hacer operativa la cobertura del seguro que se identifique al otro automotor interviniente en el siniestro no puede invocarse para liberar de responsabilidad al asegurador, dado que se trata de una disposición inserta en un contrato de adhesión que desnaturaliza o limita en forma abusiva la responsabilidad por daños -art. 37, ley de defensa del consumidor 24.240- (Adla, LIII-D, 4125), debiendo tenérsela por no convenida (CNACom, sala C, Octubre 16 de 2001) .

A igual resultado se arribó respecto de la cláusula que establece la existencia de destrucción total si el valor de los restos no supera el $20 \%$ del de venta al contado del vehículo asegurado. Así se dijo que

Es abusiva y nula la cláusula que establece la existencia de destrucción total si el valor de los restos no supera el $20 \%$ del de venta al contado del vehículo asegurado, pues constituye una infracción a las exigencias de la buena fe contractual y desnaturaliza el vínculo obligacional -art. 37, Ley 24.240 (Adla, LIII-D, 4125) (CNACom, sala A, noviembre 21 de 2000).

Uno de los aspectos en los que la jurisprudencia resulta monolítica es la que considera abusiva a la cláusula que libera al asegurador por siniestro provocado por culpa grave del conductor que no se halle en relación de dependencia laboral con el tomador. En tal sentido, se sostuvo que

La cláusula de la póliza que libera al asegurador por siniestro provocado por culpa grave del conductor que no se halle en relación de dependencia laboral es abusiva porque: la culpa grave es una delimitación subjetiva y por tal sólo referida al asegurado, la ilicitud está referida a una exclusión no admitida por el art. 158 de la ley de seguro (Adla, XXVII-B, 1677) pues empeora las condiciones de contratación para el asegurado y como se trata de un supuesto de exclusión de cobertura es de interpretación restrictiva, por lo que no se aplica cuando el conductor es un tercero por el que el asegurado deba responder (Del voto de la mayoría) (CCiv y Com Junín, abril 15 de 1997).

En igual sentido respecto de la caducidad automática del seguro de vida. En un tema tan sensible, los tribunales han dicho que

Debe tenerse por no convenida la cláusula inserta en una póliza de seguro de vida, que establece la falta de pago de la prima y produce la caducidad automática del seguro sin previo aviso al tomador o a los beneficiarios, desde que la apuntada disposición contiene una forma de renuncia o restricción de los derechos de aquéllos que conduce a desequilibrar la economía propia del contrato (CNCom., sala $\mathrm{C}$, agosto 6 de 2010).

Resulta por demás interesante lo resuelto por la Cámara Nacional de Comercio, en tanto considera nula una cláusula, en virtud de la violación del deber de información. Así sostuvo que 
Habiendo el productor de seguros informado previamente al asegurado que la cobertura asegurativa cubría los viajes al exterior por la extensión automática que operaba con la normativa del Mercosur, e incluía además los daños y lesiones a terceros transportados, debe reputarse abusiva en la cláusula que excluye este tipo de riesgos, debiendo interpretarse a favor de amparar un siniestro producido en esas condiciones atento la desinformación producida al contratante - falta de claridad y exactitud acerca de las características del seguro, deber impuesto por el art. 4 de la Ley 24.240- (CNCom., sala L, abril 28 de 2009).

Por último, vale también citar un precedente harto convulsionante, por el cual se resolvió la nulidad de una cláusula claims made. Allí se dijo que

Debe tenerse por no convenida la cláusula claims made inserta en un contrato de seguro de responsabilidad médica, ya que limita temporalmente la garantía asegurativa en un modo no previsto por la ley ampliando los derechos del asegurador $y$ restringiendo los del asegurado, siendo inadmisible que la prescripción derivada de la "mala praxis" profesional pueda impulsar a una solución arbitraria e irrazonable, porque frente a ella el alea de la aseguradora se reduce a plazos tales que la propuesta deviene inaceptable (CNCiv., sala C, Mayo 2 de 2006).

\section{PRESCRIPCIÓN}

En la actualidad, el debate se centra en el choque entre el plazo prescriptivo establecido por la Ley 17.418 en su artículo 58, que establece que «Las acciones fundadas en el contrato de seguro prescriben en el plazo de un año, computado desde que la correspondiente obligación es exigible», y el artículo 50 (modificado por la Ley 26.361) de la Ley 24.240 que dispone
Prescripción. Las acciones judiciales, las administrativas y las sanciones emergentes de la presente ley prescribirán en el término de TRES (3) años. Cuando por otras leyes generales o especiales se fijen plazos de prescripción distintos del establecido precedentemente se estará al más favorable al consumidor o usuario. La prescripción se interrumpirá por la comisión de nuevas infracciones o por el inicio de las actuaciones administrativas o judiciales.

Así entonces, nuestros tribunales han resuelto que

El plazo de prescripción trienal establecido en la Ley 24.240 debe prevalecer sobre el establecido en el artículo 58 de la ley de seguros (Adla, LIII-D, 4125; XXVII-B, 1677), pues el orden público que informa el artículo $3 .^{\circ}$ de la ley de defensa del consumidor hace que todo contrato de consumo -en el caso, un de seguro de vida y capitalización- deba regirse por los preceptos que en el caso resulten más favorables a esa parte más débil de la relación negocial (Cámara de Apelaciones en lo Civil y Comercial de Santa Fe, sala I, Octubre 4 de 2006).

También han resuelto que «es aplicable a las acciones de daños y perjuicios originadas en un contrato de transporte terrestre de pasajeros el plazo de prescripción establecido por el artículo 50 de la Ley de Defensa del Consumidor -Ley 24.240 modificada por la Ley 26.361» (Cámara Nacional de Apelaciones en lo Civil, marzo 12 de 2012).

\section{LA VÍCTIMA COMO CONSUMIDOR}

Mucho se había discutido, previo a la reforma de la Ley 26361, si la víctima de un accidente, que no era contratante del servicio, podía ser consumidora y, con ello, invocar los beneficios de la norma tuitiva.

Sobre este punto debió expedirse la Cámara $5^{\mathrm{a}}$. de Apelaciones en lo Civil, Comercial, Minas, de Paz y Tributaria de Mendoza, la cual recordó que 
Desde otra vertiente, ahora legislativa, se suma un nuevo ingrediente con el dictado de la Ley 26.361 (BO 7/4/2008) que modifica el anterior texto del Artículo $1^{\circ}$ de la Ley 24.240 Ley de Defensa del Consumidor, cuyo texto rezaba "La presente ley tiene por objeto la defensa de los consumidores o usuarios. Se consideran consumidores o usuarios, las personas físicas o jurídicas que contratan a título oneroso para su consumo final o beneficio propio o de su grupo familiar o social.

El nuevo texto, además de ampliar y precisar la calidad de "consumidor", agrega un segundo párrafo que reza "Se considera asimismo consumidor o usuario a quien, sin ser parte de una relación de consumo, como consecuencia o en ocasión de ella adquiere o utiliza bienes o servicios como destinatario final, en beneficio propio o de su grupo familiar o social, y a quien de cualquier manera está expuesto a una relación de consumo". Dicha normativa de defensa del consumidor, al encontrar sustento constitucional en la letra del Artículo 42, no sólo permite una nueva interpretación de la cuestión relativa a la franquicia, sino que impone tal revisión, cambiando sustancialmente el ángulo del análisis, en tanto la víctima quien no es parte de la relación de consumo (del contrato) requiere su protección sin serle oponible el criterio clásico contractual emergente de los Artículos 1197 y ccs. del Código Civil.

Tenemos, entonces, que como nos dice Lorenzetti (en "Consumidores", Rubinzal Culzoni, 2003, pág. 107) los preceptos tuitivos del sistema de defensa del consumidor abarcan no sólo al que paga un bien o servicio, sino a todo aquél que se sirve de él, de modo que la responsabilidad solidaria del art. 40 de la Ley 24.240 se expande como principio general, porque así lo impone la realidad y la necesidad de protección. La interpretación debe hacerse en forma amplia, extensiva a otros supuestos no previstos ( Farina, 2004, pp. 1 y 28) ${ }^{7}$.

7 Sobre este punto debió expedirse el fallo de la Cámara 5 ta. de Apelaciones en lo Civil, Comercial, Minas, de Paz y Tributaria de Mendoza (Junio 4 de 2012).
En tanto, la Cámara Nacional Civil, al expedirse respecto de la cláusula que limita irrazonablemente el monto de cobertura por daños a terceros, sostuvo que

En el presente caso nos encontramos frente a un supuesto de una cláusula limitativa de responsabilidad donde se establece en la póliza la cobertura de la responsabilidad civil con límites de $\$ 30.000$ por persona y $\$ 13.611$ por daños materiales, previendo un máximo por acontecimiento de $\$ 60.000$ (ver fs. 72, fecha de emisión de la póliza el 3 octubre de 2003, con vencimiento el 3 enero 2004). Opinamos que esa cláusula resulta irrazonable; además de contraponerse a una norma de orden público que establece la obligatoriedad de un seguro de responsabilidad civil contra terceros".

Aceptar esta cláusula limitativa de responsabilidad implicaría desnaturalizar las obligaciones que se encuentran a cargo de la aseguradora en un contrato de seguro "normal", al violentar los deberes esenciales o naturales del contrato, o sea, su fin. Anotamos que ello frustraría las expectativas razonables que legítimamente tienen los consumidores de seguros, contrariando las raíces del contrato. Es evidentemente una cláusula abusiva que traslada sus efectos a los damnificados.

Es que la Ley 26.361 amplió el concepto de consumidor y lo ha extendido a quien sin ser parte de una relación de consumo, como consecuencia o en ocasión de ella, utiliza servicios como destinatario final y a quien "de cualquier manera está expuesto a una relación de consumo" (art. $1^{\circ}$, Ley 26.361). A raíz de ello, resulta totalmente inaplicable el concepto de efecto relativo de los contratos (arts. 1195 y 1199 del C. Civil) respecto de las personas que están expuestas a dichas relaciones de consumo.

Debe tenerse presente que una reciente resolución de la Superintendencia de Seguros 
de la Nación ( $\mathrm{N}^{\circ} 35.614$ del 11/02/2011) estableció que esta entidad, "para aprobar los elementos técnicos-contractuales, analizará si dichas condiciones se ajustan a las normas constitucionales, legales y reglamentarias vigentes". Agregando que "especialmente se considerará la adecuación de tales elementos técnicos-contractuales con las disposiciones de las leyes $\mathrm{N}^{\circ} 17.418$, 20.091 y 24.240 y demás legislación general aplicable (...)" Estas disposiciones nos otorgan un marco interpretativo acorde con la solución que propiciamos $y$, sobre todo, que protege al consumidor en todas sus dimensiones.

La víctima pasa a ser, entonces, lo que se conoce en doctrina como "bystander" y ello trae aparejado que se encuentre protegida por los derechos que el estatuto del consumidor le acuerda.

Desde ese enfoque, la cláusula de limitación de cobertura en una suma tan exigua como la pactada entre el asegurado y la citada en garantía, "desnaturaliza las obligaciones o limita la responsabilidad" de la aseguradora, y por ende, debe tenérsela por no convenida (art. 37 inc. $1^{\circ}$, Ley 24.240, reformada por la Ley 26.361; conf. precedente de esta Sala en su actual composición, in re "González, Domingo y otro c/ Villarpando Inca, O. y otros; s/ daños" del 4/2/2010; ver jurisprudencia SCJ de la Provincia de Buenos Aires, in re "Díaz, Alicia Susana c/ Moreno, Carlos s/ Daños y perjuicios", LZ 64095 RSD-338-7, del 4/10/2007, elDial. com W190FA) (CNCiv, sala H, agosto 12 de 2011).

Observe el lector, que en virtud de considerar a la víctima consumidor, en los términos del artículo 1 de la Ley 24.240, se resolvió decretar la invalidez de una cláusula inserta en un contrato que lo afectaba de manera directa, pero en el cual no había tenido participación alguna. De esta manera, se derriban los efectos limitados del contrato que establecía el régimen del Código
Civil, para avanzar en la tutela de quien en ese acto reviste la calidad de débil jurídico.

\section{CONCLUSIÓN}

Tal como pudo observarse del rápido punteo que hemos efectuado de las distintas aristas que la temática genera, el debate no es menor y escapa del ámbito académico para impactar de lleno en la construcción del marco social y económico. Y estas son solo algunas de las cuestiones que la relación entre ambas normas aún genera en la República Argentina, lo que explica la vehemencia de las posturas de ambos sectores.

Es que el Derecho del Consumo ha revolucionado las viejas estructuras propias del siglo XVIII, a la luz de las cuales se erigieron las normas rectoras del sistema legal argentino, a partir del aún vigente (aunque por poco tiempo más a raíz de la prácticamente segura aprobación del Código Civil 2014 que cuenta ya con media sanción) Código Civil de Vélez Sarsfield, sancionado en el año 1869, pero construido con base en los autores que apuntalaron el Código Napoleónico de 1804.

Y es tan fuerte el cimbronazo que la norma ha generado, que en todos los campos pétreos se dan batallas como la aquí expuesta, tendientes a aggiornar las viejas odres, a los nuevos tiempos.

\section{REFERENCIAS}

Álvarez, F. M. (2001) Las personas jurídicas ¿̇son consumidores? La Ley, 2001-B, 1165 V, 695.

Álvarez, F. M. (2008). El Derecho del Consumo como centro del sistema regulador del mercado. LLCABA (diciembre), 330.

Álvarez, F. M. (2008). El impacto procesal y de fondo de la nueva Ley 26.361 en el Derecho del Consumo. Sup. Esp. Reforma de la Ley de defensa del consumidor (abril), 25. 
Álvarez, F. M. (2009). La buena fe en la Ley 24.240. La Ley 2009-C, 1271.

Álvarez, F. M. (2009). La consistencia de los daños punitivos. La Ley, 2009-B, 1156, II, 361.0

Álvarez, F. M. (2009). Los daños punitivos y su paulatina y exitosa consolidación. La Ley, 2010F, 397.

Álvarez, F. M. (2010). Las cláusulas abusivas en el derecho español y argentino. Análisis comparativo. RCyS 2010-VII, 253.

Álvarez, F. M. (2013). La protección constitucional de los "intereses económicos" de los consumidores", Sup. Const. 2013 (febrero), 35, La Ley, 2013-A, 395.

Bauman, Z. (2005). Trabajo, consumismo y nuevos pobres. Barcelona: Gedisa.

Cámara 5a de Apelaciones en lo Civil, Comercial, Minas, de Paz y Tributaria de Mendoza. (Argentina). Pecoraro, Sandra Marcela c. Rodríguez, Leonardo Miguel s/daños y perjuicios). RCyS 2012-VIII, 249, LLGran Cuyo 2012 (agosto), 713 con nota de José Luis Correa. (Junio 4 de 2012).

Cámara 6a de Apelaciones en lo Civil y Comercial de Córdoba. (Argentina). "Córdoba, Dora Manuela c. Caja de Seguros S.A. s/ ordinario - cobro de pesos - recurso de apelación", 09/11/2011, La Ley Online.

Cámara 6ta. de Apelaciones en lo Civil y Comercial de Córdoba. (Argentina). "Basualdo, Adolfo Rubén c. Seguros Bernardino Rivadavia Cooperativa Limitada", 08/10/2009, LLC 2010 (junio) , 559.

Cámara de Apelaciones Civil y Comercial de Formosa. (Argentina). "Asoc. Mutual de Empleados del Bco. Pcia. Fsa.”, 03/03/2011, LLLitoral 2011 (junio), 570.

Cámara de Apelaciones en lo Civil y Comercial de Dolores. (Argentina). Cancio, Carlos Fabián c. Mapfre Argentina Seguros SA s/daños y perjuicios. LLBA 2012 (marzo), 206, RCyS 2012VI, 241 con nota de Gustavo Raúl Meilij. (Octubre 25 de 2011).

Cámara de Apelaciones en lo Civil y Comercial de Lomas de Zamora, sala I. (Argentina). "Gómez de Olivera Jorge Ruben c. Federación Patronal Seguros S.A. s/daños y perj. autom. s/lesiones", 22/05/2012, ED 21/06/2012, 7, LLBA 2012 (junio), 557, RCyS 2012-VII, 248, RCyS 2012$\mathrm{X}, 223$

Cámara de Apelaciones en lo Civil y Comercial de Pergamino. (Argentina). "Medina, Juan Manuel c. Club Viajantes Pergamino s/daños y perj. del. /cuas. (exc. uso aut. y estado)", 28/02/2012, LLBA 2012 (abril), 341, RCyS 2012-V, 269.

Cámara de Apelaciones en lo Civil y Comercial de Santa Fe, sala I. (Argentina). "Martínez, Walter César y otra c. Aetna Vida S.A.", 04/10/2006, RCyS 2006, 1258, IMP 2006-23-24, 2994, LLLitoral 2006, 1451.

Cámara de Apelaciones en lo Civil y Comercial de Santa Fe, sala I. (Argentina). Martínez, Walter César y otra c. Aetna Vida S.A. RCyS 2006, 1258, IMP 2006-23-24, 2994, LLLitoral 2006, 1451. (Noviembre 4 de 2006).

Cámara de Apelaciones en lo Civil, Comercial y de Minería de Bariloche. (Argentina). "Girgenti, Federico José c. Ruau, Sergio Luis”, 04/04/2011, La Ley Online.

Cámara Nacional Civil y Comercial Federal (CNFed. Civ. y Com.). Sala I. (Argentina). "Cervecería y Maltería Quilmes c. Casa Isenbeck", RCyS 2005-VIII, 31, con nota de Fulvio G. Santarelli - ED 214, 256 - JA 2005-III, 353.

Cámara Nacional de Apelaciones en lo Civil, en pleno. (Argentina). Sáez González, Julia del Carmen c. Astrada, Armando Valentín y otros s/ daños y perjuicios (Acc. Trán. c/ Les. o Muerte). LA LEY 2012-B , 378 con nota de Fernando Alfredo Sagarna, LA LEY 2012-B , 565 con 
nota de Félix A. Trigo Represas, RCyS 2012$\mathrm{V}, 13$ con nota de Graciela Messina de Estrella Gutiérrez, DJ 02/05/2012, 83, ED 03/05/2012, 2, DJ 13/06/2012, 5 con nota de Alejandro Borda. (Marzo 12 de 2012).

CCiv y Com Junín. (Argentina). D, J. y otro c. D., A. C. LLBA 1997, 852. (Abril 15 de 1997).

CNACom, sala A. (Argentina). Liotta, Leonardo F. c. Compañía Argentina de Seguros Visión. LL 2001-B, 321 - DJ 2001-2, 271. (Noviembre 21 de 2000).

CNACom, sala C. (Argentina). Villalba, Gladys I. c. Vanguardia Cía. de Seguros. LL 2001-F, 671 - JA 2002-II, 807 - DJ 2001-3, 758. (Octubre 16 de 2001)

CNCiv, sala H. (Argentina). Bustamante, Omar Rubén y otro c. Ortega, Santiago Nicolás y otros $\mathrm{s} /$ daños y perjuicios (acc. trán. c/ les. o muerte). La Ley Online. (Agosto 12 de 2011).

CNCiv., sala C. (Argentina). Barral de Keller Sarmiento, Graciela c. G., J. A. y otros. RCyS, 2006, 1014, con nota de Domingo M. López Saavedra; Roberto A. Vázquez Ferreyra LA LEY, 2006-E, 2, con nota de Waldo A. R. Sobrino LA LEY, 2006-E, 399, ED, 221-159, AR/JUR/1750/2006. (Mayo 2 de 2006).

CNCiv., sala L, "Fernández, Liliana Mónica y otros c. Bonavera, Walter Oscar y otros. (Argentina). 28/04/2009, con nota de José Luis Correa, LA LEY, 2009-E, 435, ED, 235-85.

CNCom., sala C. (Argentina). Gualco, Alba Clara y otro c. Provincia Seguros S.A. Con nota de Guido E. Lichtman, LA LEY, 2011-A, 23, AR/ JUR/39672/2010. (Agosto 6 de 2010).

CNCom., sala L. (Argentina). Fernández, Liliana Mónica y otros c. Bonavera, Walter Oscar y otros s/daños y perjuicios. (Abril 28 de 2009).

Farina, J. M. (2000). Defensa del consumidor y del usuario. Buenos Aires: Astrea.
Ghersi, C. A. (2005). Contratos de consumo. Buenos Aires: Astrea.

Graziano, W. (2007). Hitler ganó la guerra. Buenos Aires: Planeta.

Gregorini, E. L. (2009). El seguro y la relación de consumo. La Ley, 2009-A, 1130.

Junyent, F.; \& Del Cerro, C. (2010, junio 14). Aspectos procesales en la ley de defensa del consumidor. La Ley, 1.

Juzgado Nacional de 1a Instancia en lo Civil núm. 110. (Argentina). G., M. J. c. Honda Automóviles de Argentina S.A. y otro LA LEY 21/07/2008, 21/07/2008, 11 - LA LEY 21/07/2008). (Julio 3 de 2008).

Lima, C. (2000). Contratos no Código de Defesa do Consumidor. O novo regime das relaçôes contratuais. Revista dos Tribunais, 254 y ss.

López, D. (2010a). El plazo de prescripción en el contrato de seguro y la preeminencia de la ley de seguros sobre la ley de defensa del consumidor. RCyS 2010-IV, 95.

López, D. (2010b). La adecuada protección de los derechos del asegurado en la ley de seguros y en las leyes 20.091 y 22.400. La Ley, 2010-F, 1104.

López, D. (2010c). La adecuada protección de los derechos del asegurado en la ley de seguros y en las leyes 20.091 y 22.400. La Ley, 2010-F, 1104.

López, D. (2011). La adecuada protección de los asegurados. La resolución 35.840 S.S.N. La Ley, 2011-E, 711.

López, D. (2012). Ley de Seguros 17.418. Comentada. Buenos Aires: Ed. La Ley.

Lorenzetti, R. L. (2003). Consumidores. Santa Fe (Argentina): Rubinzal-Culzoni.

Parral, P. R.; \& Sartini, M. S. (2011). El concepto de consumidor en el contrato de seguro: senti- 
do y alcance de la reforma de la Ley 26.361. RCyS 2011-IX, 26.

Pasqualotto, A. (1993, abril-junio). Defesa do consumidor. Revista Direito do consumidor, 6.

Santarelli, F. G. (2010). Comentario de la obra. En Sobrino, W. A. R. Consumidores de seguros. La Ley, 2010-D, 1351.

Sobrino, W. A. R. (2009a). Consumidores de seguros. Buenos Aires: Ed. La Ley.

Sobrino, W. A. R. (2009b). Consumidores de Seguros y la inoponibilidad de la franquicia: ¿El inicio de una historia? La Ley, 2009-C, 380.

Sobrino, W. A. R. (2009c). Una norma fundamental para protección de los consumidores. $\mathrm{El}$ art. 56 de la ley de seguros. La Ley, 2009-E, 63.

Sobrino, W. A. R. (2010). La prescripción en materia de seguros. Según la ley de defensa del consumidor. La Ley, 2010-B, 772.

Sobrino, W. A. R. (2011a). Las modificaciones a la ley de seguros por aplicación de la ley de defensa del consumidor. RCyS 2011-II, 37.

Sobrino, W. A. R. (2011b). Un 'nuevo orden público de seguros'. La ley de seguros es el 'piso mínimo' para proteger al 'consumidor de seguros'. La Ley, 2011-B, 726.

Sobrino, W. A. R. (2011c). Consumidores de seguros (Aplicación de la ley de defensa del consumidor a los seguros). RCyS 2011-VI, 3.

Sobrino, W. A. R. (2011d). Prescripción: Contrato de transporte y defensa del consumidor. La Ley, 2011-D, 1080.

Sobrino, W. A. R. (2011e). La aplicación de la Ley de Defensa del Consumidor por sobre la Ley de Seguros: una tendencia jurisprudencial que se consolida. RCyS 2011-XII, 79.

Stiglitz, R. S.; Compiani, M. F.; \& Piedecasas, M. (2011). La necesidad de modificar la ley de seguros. La Ley, 2011-F, 813.

Tolosa, P. (2010). El seguro obligatorio y la franquicia en un contexto de insolvencia: ¿nuevas soluciones en la ley de defensa del consumidor? RCyS 2010-II, 139.

Valdés, G. J. (2011). La protección del consumidor en el derecho de seguros. LLC 2011 (agosto), 739.0

Vela, C. I. (2003). Derecho Penal Económico. La Ley, 2003-D, 1368. 